\title{
BANGUN JIWA KEWIRAUSAHAAN DAN KREATIFITAS MELALUI PELATIHAN KERAJINAN TALIKUR BAGI IBU RUMAH TANGGA DI LAMPUNG TIMUR
}

\author{
Yeni Rahmawati ES ${ }^{1 *}$, Ira Vahlia ${ }^{2}$ \\ ${ }^{1,2}$ Pendidikan Matematika, Universitas Muhammadiyah Metro, Indonesia \\ 1'yeni.rahmawati1988@yahoo.com, ${ }^{2}$ iravahlia768@yahoo.co.id
}

\begin{abstract}
ABSTRAK
Abstrak: Kerajinan talikur saat ini sedang digemari oleh kaum hawa, baik itu remaja ataupun wanita dewasa. Namun, tak semua orang dapat membelinya karena keterbatasan ekonomi mengingat harganya yang tidak murah. Oleh karena itu, kegiatan pengabdian ini dilakukan untuk memberikan pelatihan bagaimana cara membuat kerajinan talikur. Jadi, peserta dapat membuat sendiri kerajinan talikur sesuai yang diinginkan. Metode yang dilakukan dalam kegiatan ini yakni dengan pelatihan langsung (ceramah, demonstrasi, dan tanya jawab) dan pendampingan. Hasil dari pengabdian ini adalah peserta memiliki pengetahuan dan ketrampilam membuat kerajinan talikur dalam berbagai bentuk dan model.
\end{abstract}

Kata Kunci: Kewirausahaan; Kreatifitas; Kerajinan Talikur

Abstract: Talikur craft is currently favored by women, both teenagers and adult women. However, not everyone can buy it because of economic limitations given the price is not cheap. Therefore, this dedication activity is carried out to provide training on how to make handicraft Talikur. So, the participants can make their own handicraft as desired. The method used in this activity is through direct training (lectures, demonstrations, and question and answer) and mentoring. The result of this dedication is that participants have the knowledge and skills to make handicrafts in various forms and models.

Keywords: Entrepreneurship, Creativity, Talikur Crafts

\section{A. LATAR BELAKANG}

Angkatan kerja pada Februari 2018 sebanyak 4.395,9 ribu orang, naik sebanyak 323,4 ribu orang dibanding Agustus 2017 dan naik 124,7 ribu orang dibanding Februari 2017. TPT Februari 2018 sebesar 4,33 persen, turun sebesar 0,10 poin dibanding TPT Februari 2017 (4,43 persen). Secara absolut jumlah pencari kerja (pengangguran terbuka) mengalami kenaikan sebanyak 1,4 ribu orang atau bertambah 0,73 persen selama setahun terakhir. Sektor yang paling banyak mengalami pengurangan tenaga kerja ialah Industri sebanyak 73.200 pekerja (Statistik \& Lampung, 2018).

Pemerintah Kabupaten Lampung Timur terus berupaya untuk mengurangi angka pengangguran, salah satu caranya adalah dengan mengembangkan usaha kecil di rumah tangga atau home industri. Home industry atau usaha di rumah adalah tempat tinggal yang merangkap tempat usaha, baik itu berupa usaha jasa, kantor hingga perdagangan(Wendri Wiratsiwi, Mega Puspita Sari, 2018). Industri merupakan kegiatan ekonomi dimana dalam kegiatannya mengolah bahan 
mentah menjadi bahan setengah jadi, atau pun bahan setengah jadi menjadi bahan jadi yang bisa langsung dikonsumsi oleh konsumen (Vahlia \& Lelawati, 2019). Industri rumah tangga diharapkan berperan dalam memecahkan masalah-masalah pengembangan industri di Indonesia (Joesyiana, 2017). Karena industri rumah tangga mempunyai jumlah unit usaha yang jauh lebih baik dibandingkan kelompok usaha industri sedang dan industri besar. Di era jaman sekarang masih terdapat juga sebagian perusahaan yang hanya mempercayakan pekerjaan tersebut kepada kaum laki-laki saja sehingga kaum perempuan tidak bisa mengembangkan potensi yang ada pada dirinya, sehingga perlu wadah khusus yang mampu menampung aspirasi perempuan-perempuan sehingga potensinya bisa tersalurkan dengan baik.

Ibu-ibu yang tergabung dalam Kelompok Kencana Desa Sumbergede Ngapur Kecamatan Sekampung Kabupaten Lampung Timur rata-rata memiliki kesibukan dalam mengurus rumah tangga. Oleh karena itu, dilaksanakan pelatihan ekonomi kreatif yang dapat mengembangkan kreativitas ibu rumah tangga. Salah satu produk yang paling digemari yaitu kerajinan talikur. Seni kerajinan makrame/talikur adalah seni kerajinan menggunakan tali sebagai bahan dasarnya dan merupakan salah satu cabang seni rupa terapan(Nadliroh \& Dewi, 2017). Seni Kerajinan Makrame/tali kur adalah seni kerajinan yang memanfaatkan tali dan benang untuk menciptakan aneka ragam aksesoris dan produk (Ujung \& Chairani, 2018)

Kerajinan talikur merupakan salah satu jenis hasil kerajinan tangan yang memiliki nilai eksklusifitas tinggi. Ekslusif karena dari segi bentuk atau model, kerajinan ini menawarkan berbagai macam bentuk yang sangat variatif dengan didukung banyak pilihan warna. Selain itu, kerajinan talikur tidak memerlukan waktu khusus, ibu-ibu bisa mengerjakannya sambil nonton televisi, mengobrol dengan keluarga, atau sambil menjaga anak. Ibu-ibu rumah tangga yang menganggur bisa menjadi lebih produktif karena memiliki waktu yang lebih luang untuk menambah penghasilan keluarga dengan kegiatan yang bermanfaat .

Kerajinan talikur saat ini makin banyak yang menggemari. Hasil pembuatan kerajinan talikur menunjukkan perubahan yang signifikan dengan adanya berbagai desain dan model kerajinan talikur yang bervariasi dan memiliki nilai ekonomis (jual) lebih tinggi (Suhartono, Andriyani, \& Murniasih, 2019). Diberbagai toko tas dan aksesoris juga telah banyak dijual produk-produk talikur baik itu itu berupa tas, dompet, maupun kantong $\mathrm{Hp}$ dengan berbagai bentuk model dan warna yang menarik sehingga cocok dipakai wanita pada berbagai situasi. Banyak yang membelinya untuk digunakan sendiri atau untuk diberikan kepada orang yang disayang.

Keunggulan talikur adalah bahannya yang kuat menjadikannya lebih awet dan tahan lama. Serta model yang unik dengan rangkaian tali yang 
disusun rapi dan dimodifikasi dengan tambahan rajutan bungan yang dipadukan oleh talikur akan menjadikan talikur lebih cantik dipakai oleh penggunanya. Kreatifitas sangat diperlukan dalam pembuatan talikur ini. Karena semakin tinggi tingkat kreatifitas pembuatnya maka semakin bagus pula model yang dihasilkan dan akan semakin mahal pula harganya. Karena warnanya yang cerah dan sangat cantik, talikur dapat dibuat untuk berbagai macam aksesoris seperti gelang, bandana, ikat pindang, dan kalung.

Melalui kegiatan ini, diharapkan bisa meningkatkan keterampilan dan membuka lapangan kerja bagi ibu-ibu rumah tangga sehingga bisa tercipta peluang usaha mandiri yang bergerak di sektor industri rumah tangga atau home industry, termasuk ikut meningkatnya daya kreativitas dalam berkarya serta inovasi ibu-ibu rumah tangga dalam berekspresi yang selanjutnya bisa menemukan hasil karya yang bermanfaat dan tepat guna. Pelatihan merupakan bagian pendidikan yang terkait proses belajar untuk meningkatkan pengetahuan dan keterampilan individu, dilakukan dalam waktu yang relatif singkat, secara sistematis dan terorganisasi dengan lebih mengutamakan praktek dari pada teori,sehingga individu tersebut dapat berkompetensi baik dalam pekerjaan, kehidupan, maupun dalam persaingan global yang semakin erat (Khustiyana \& Faidah, 2016). Selain itu, mereka bisa menciptakan wirausaha dalam pembuatan tas dari talikur atau tali sepatu yang berujung pada meningkatnya ekonomi dan kesejahteraan keluarga, agar mereka tidak perlu bekerja mencari uang untuk tambahan ekonomi keluarga dengan mengesampingkan tugas utama ibu sebagai pengasuh anak. Kegiatan ini merupakan bentuk implementasi dari program peningkatan ekonomi produktif yang merupakan salah satu program pengentasan kemiskinan dan juga sebagai upaya untuk mengatasi masalah pengangguran.

\section{B. METODE PELAKSANAAN}

Metode yang dilakukan dalam kegiatan pengabdian ini adalah dengan memberikan pelatihan langsung (ceramah, demonstrasi, dan tanya jawab) dan pendampingan kepada ibu-ibu kelompok kencana desa Sumbergede Ngapur. Desa Sumbergede Ngapur merupakan salah satu desa yang berada di kecamatan Sekampung Lampung Timur. Kegiatan ini dihadiri oleh 15 orang.

Sebelum pelatihan dilaksanakan, dilakukan persiapan dengan menyiapkan bahan-bahan yang dibutuhkan. Bahan untuk membuat kerajian ini tidak susah dicari dan dari segi harga juga tidak mahal. Alat dan bahan-bahannya yang dibutuhkan antara lain adalah :

1. Tali kur berbagai warna

2. Gunting

3. Korek api

4. Retlesting 
5. Bahan/kain polos untuk bagian dalam

6. Benang dan jarum

7. Pernak-pernik

Setelah semua bahan dan alat siap. Tahap selanjutnya adalah memulai merajut talikur menjadi bagian bagian yang akan di gabungkan menjadi sebuah barang. Ada beberapa tahapan dasar yang wajib dikuasai/dipahami. Berikut tahapannya dalam membuat talikur antara lain:

1. Pada langkah pertama cara membuat tas dari tali kur ini, bisa mengambil dua heli tali dengan panjang tali sama. Kemudian lipat tali menjadi 2 bagian dan sejajarkan. Maka akan memperoleh 4 ujung tali. Beri nomor pada tali agar lebih memudahkan, yaitu nomor 1, nomor 2, nomor 3 dan nomor 4 dari kiri ke kanan.

2. Ambil tali nomor 4 kemudian silangkan kebelakang tali lainnya menuju arah 1. Cara membuat tas dari tali kur selanjutnya ialah letakan tali nomor 1 pada bagian belakang tali 4. Sehingga urutannya menjadi nomor 4, 1, 2 dan 3 .

3. Langkah dari cara membuat tas dari tali kur selanjutnya adalah ambil ujung tali nomor 1 kemudian kunci dengan cara memasukan pada lubang dari tali nomor 3 dan 4. Selanjutnya tarik tali nomor 1 dari arah kiri dengan tali nomor 4. Hal ini dilakukan untuk mengunci dan juga melipat untuk memasukannya ke lubang belakang.

4. Kemudian tarik kuat masing-masing tali untuk mengutakan dan juga mengunci. Ini merupakan langkah dasar cara membuat tas dari tali kur. Perlu membuat dasar tas ini dengan jumlah yang genap. Hal ini agar lebar tas seimbang anatar kiri dan juga kanan. Jadi, semakin besar tas yang ingin dibuat, maka semakin banyak pula pola dasar yang harus dibuat.

5. Untuk menyambungkan 2 pola dasar tas ini, cara yang digunakan pun sama, hanya saja dua kepala yang dirangkai ini dijadikan satu dengan menjejerkan tali-tang ada. Kemudian dua utas tali pada bagian kanan dan dua utas tali pada bagian kiri atau ambil tengah tali untuk menyatukannya. Cara yang digunakan pun sama, karena untuk menyambungkannya juga perlu menggunakan 4 tali

6. Lakukan membuat pola dasar ini untuk membentuknya menjadi tas. Jka telah mebentuk kotak ataupun persegi panjang, selanjutnya hanya perlu menggabungkannya untuk membentuknya menjadi tas menggunakan benang dan jarum ataupun korek api. Namun apabila benang yang digunakan sebelumnya telah habis namun rangkaian tas belum selesai, bisa menambahkan ujung benang dengan benang lainnya menggunakan korek api. Yang perlu dilakukan adalah membakar sedikit ujung benangnya kemudian gabungkan. 
Disarankan untuk tidak terlalu lama dari waktu membakar dan menggabungkannya (Ayuningtyas, 2019).

\section{HASIL DAN PEMBAHASAN}

Pelatihan langsung dilakukan sebanyak 2 kali pertemuan, yang dihadiri 15 orang. Pelatihan pada hari pertama dilaksanakan pada tanggal 7 September 2019 pukul 09.00 - 12.00 WIB. Ibu-ibu peserta diberikan pengetahuan/informasi tentang alat dan bahan yang diperlukan. Selanjutnya diajarkan membuat dasar simpul sederhana yang selanjutnya ibu-ibu peserta diberikan kebebasan akan membuat talikur apa. Apakah akan membuat tas, dompet, tempat handphone, atau yang lain.

Pelatihan pada hari kedua dilaksanakan pada tanggal 8 September 2019 pukul 09.00 - 12.00 WIB. Hasil kerajinan talikur ibu-ibu sudah mulai nampak terlihat akan menyerupai apa. Seperti ada yang akan membuat tas dan dompet.

Untuk selanjutnya, dilakukan pendampingan secara personal oleh pengabdi. Pendampingan ini dilakukan selama 1 bulan. Jadi, pengabdi setiap seminggu sekali mendatangi ibu-ibu peserta untuk melihat proses pembuatan talikur sampai selesai. Dengan adanya pelatihan talikur dapat memotivasi para masyarakat khususnya remaja putri untuk terus mengembangkan ide dalam berkreasi dan dapat menjadikan hasil karya tersebut untuk meningkatkan perekonomian yang dapat bersaing dengan produk-produk luar (Zulida \& Purwati, 2017). Berikut adalah dokumentasi selama kegiatan berlangsung.

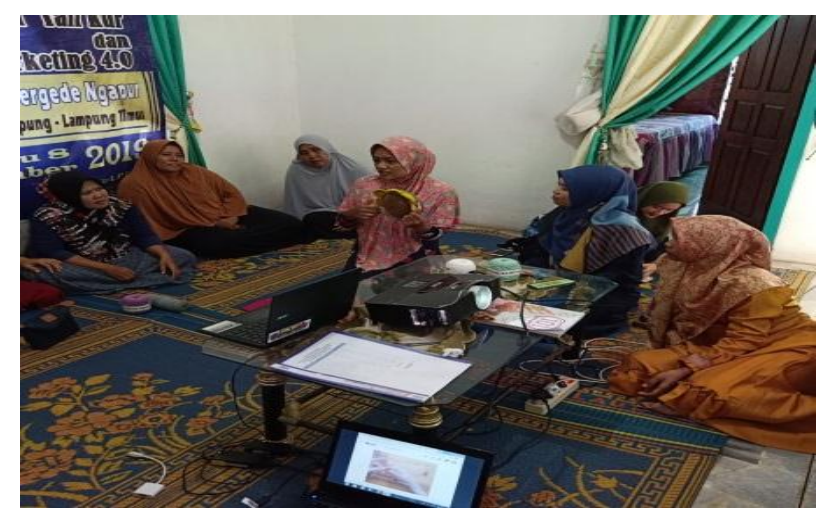

Gambar 1. Pengenalan Bahan dan Alat talikur

Gambar 1 merupakan kegiatan hari pertama pengabdian, yang mana tim pengabdi memberikan informasi atau mengenalkan bahan dan alat untuk kerajinan talikur kepada ibu-ibu peserta. 
Yeni Rahmawati ES, Bangun Jiwa Kewirausahaan...
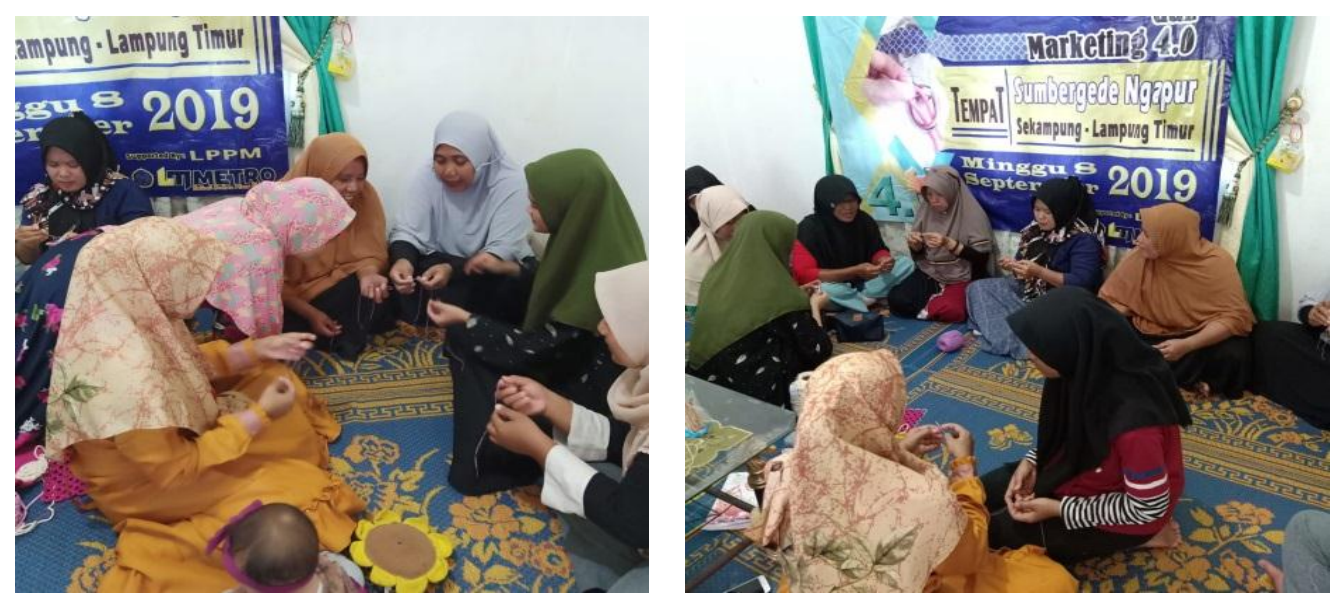

Gambar 2. Membuat Dasar Simpul

Gambar 2 merupakan kegiatan membuat dasar simpul untuk mulai membuat talikur. Setelah tim pengabdi mendemonstrasikan cara membuat dasar simpul, ibu-ibu peserta mempraktekkan langsung membuat dasar simpul.
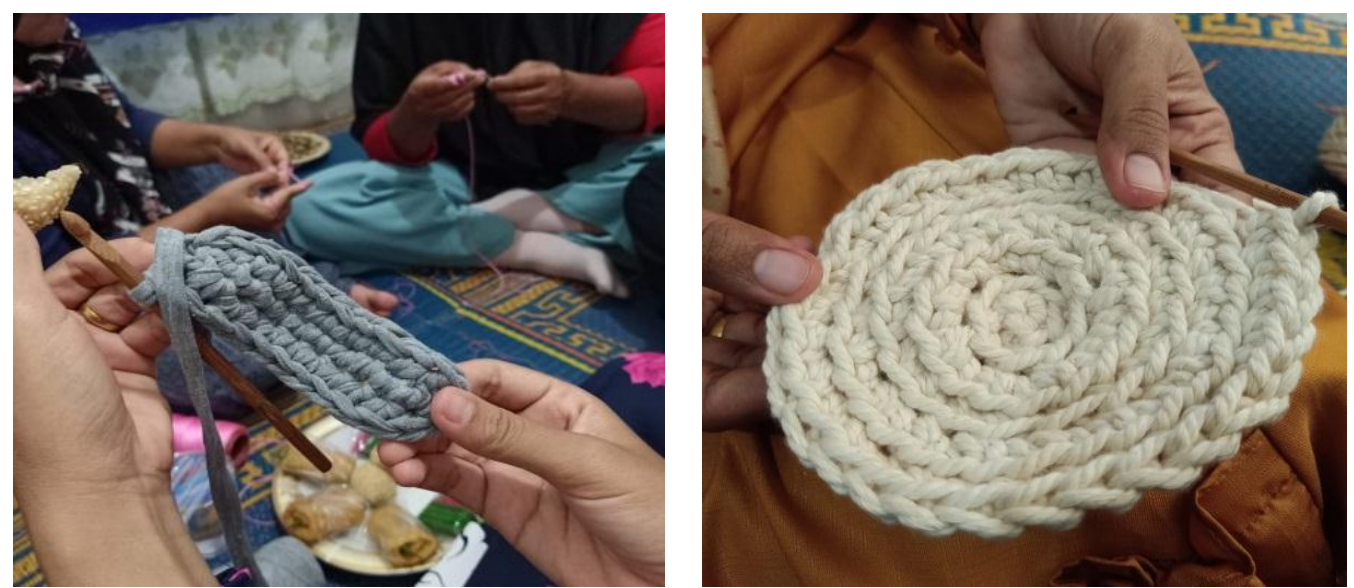

Gambar 3. Beberapa Talikur Alas tas dan Dompet

Gambar 3 merupakan beberapa contoh talikur bagian alas yang nantinya akan membentuk tas dan dompet.
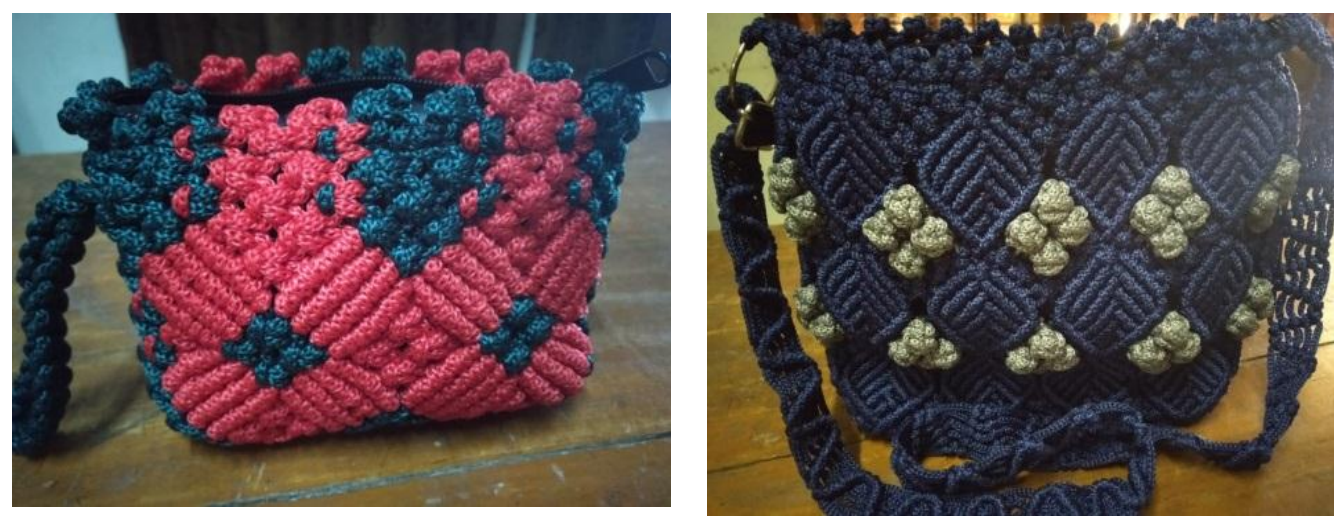

Gambar 4. Beberapa Talikur yang sudah jadi yakni tas dan dompet

Gambar 4 adalah beberapa sampel hasil akhir hasil kerajinan talikur dari ibu-ibu peserta yang berupa tas dan dompet. 


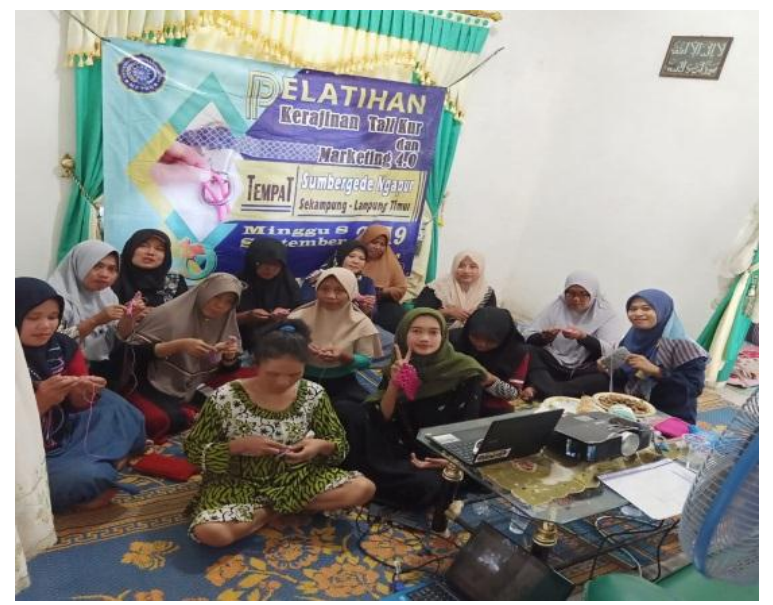

Gambar 5. Foto bersama Ibu-Ibu Kelompok Kencana

Gambar 5 adalah ibu-ibu kelompok Kencana desa Sumbergede Ngapur bersama tim pengabdi.

\section{SIMPULAN DAN SARAN}

Ibu-ibu peserta kegiatan pelatihan merasa senang dan bersyukur karena diberikan ilmu yang sangat bermanfaat sekali bagi mereka. Dengan pelatihan yang diberikan, mereka dapat membuat sendiri kerajinan talikur dalam berbagai variasi bentuk dan model berdasarkan kreatifitas mereka. Dengan demikian, jiwa kreatifitas mereka mulai muncul. Selain membuat kerajinan talikur untuk diri sendiri, juga bisa untuk diberikan kepada orang lain sebagai hadiah atau kado. Selain itu, bisa menjadi sumber penghasilan dengan menjualnya ke orang lain. Dengan demikian, jiwa kewirausahaan mereka mulai terbangun.

\section{UCAPAN TERIMA KASIH}

Tim pengabdi mengucapkan terima kasih kepada semua pihak yang telah membantu kegiatan pelatihan ini, khususnya kepada Lembaga Pengabdian Pada Masyarakat (LPPM) Universitas Muhammadiyah Metro yang telah mendanai kegiatan pengabdian ini sehingga terlaksana dengan baik.

\section{DAFTAR RUJUKAN}

Ayuningtyas, N. (2019). Cara Membuat Tas dari Tali Kur, Mudah bagi Pemula.

Joesyiana, K. (2017). Strategi Pengembangan Industri Rumah Tangga Di Kota Pekanbaru. Jurnal Valuta, 3(1), 159-172.

Khustiyana, R., \& Faidah, M. (2016). Pelatihan Keterampilan Membuat Aksesoris Dari Bahan Dasar Kain Perca Dan Manik - Manik Bagi Eks Wanita Tuna Susila Pasca Penutupan Lokalisasi Jarak Surabaya. 05(1), 8-14.

Nadliroh, K., \& Dewi, R. (2017). Pelatihan Pembuatan Tas Tali Kur Sebagai Pemberdayaan Perempuan Di Desa Puhsarang Kecamatan Semen Kabupaten Kediri. Jurnal Ilmiah Teknik Dan Industri., 2(2), 1-8.

Statistik, B. P., \& Lampung, P. (2018). Keadaan Ketenagakerjaan Provinsi Lampung Februari 2018, 1-13.

Suhartono, Andriyani, D., \& Murniasih, C. (2019). Pemberdayaan Perempuan Pengrajin Talikur. Prosiding seminar nasional pengabdian kepada 
masyarakat universitas Terbuka (pp. 86-96).

Ujung, C. S., \& Chairani. (2018). Analisis Karya Seni Kerajinan Anyam Tali Kur Siswa Kelas X Madrasah Aliyah Negeri 1 Stabat Berdasarkan Teknik Bentuk Dan Warna. JurnalSeni Rupa, 71), 66-93.

Vahlia, I., \& Lelawati, N. (2019). Pemanfaatan E-Commerce Dalam Upaya Meningkatkan Volume Penjualan Pada Mitra Keripik Pisang Arjuna Di Yosodadi Metro Timur. Prosiding Seminar Nasional Hasil Pengabdian Kepada Masyarakat (Vol. 4, pp. 694-699).

Wendri Wiratsiwi, Mega Puspita Sari, L. A. R. (2018). Pelatihan Pembuatan Tas Dengan Teknik Makrame Kecamatan Singgahan Kabupaten Tuban. Prosiding seminar nasionalhasil penelitian dan pengabdian kepadamasyarakat III Universitas PGRI Ronggolawe Tuban (Vol. 3, pp. 501-504).

Zulida, E., \& Purwati. (2017). Meningkatkan Penggunaan Bahasa Inggris Melalui Kerajinan Tangan Tali Kur Bagi Remaja Putri Di Gampong Blang. Jurnal Vokasi, 1(2), 94-97. 